\title{
Disfigurement: the challenges for identity and the strategies for coping
}

\author{
Rusi Jaspal \\ Institute for Science and Society, School of Sociology and Social Policy, University of \\ Nottingham
}

\begin{abstract}
Living with disfigurement can constitute a psychologically challenging position for both adults and young people alike. The present paper explores the potential implications of living with disfigurement for identity through the novel application of identity process theory, a socio-psychological theory of identity threat, to the topic of disfigurement. The theory argues that individuals need to perceive appropriate levels of self-esteem, distinctiveness, continuity, self-efficacy, meaning, belonging and coherence, and that insufficient levels of these principles will induce identity threat. Firstly, the paper outlines those principles most susceptible to threat among individuals living with disfigurement. Secondly, it considers strategies which may be implemented by the threatened individual as a means of coping with identity threat associated with disfigurement, as well as the efficacy of these strategies. The primary focus of the paper lies within the identification of what threatens identity and how health care institutions can facilitate and encourage effective coping strategies among individuals living with disfigurement.
\end{abstract}

Keywords: disfigurement; identity; threat; coping; identity process theory; social psychology

Submitted to Social Psychological Review

* Correspondence: Dr Rusi Jaspal, Institute for Science and Society, School of Sociology and Social Policy, Law and Social Sciences Building, University of Nottingham, Nottingham NG7 2RD, United Kingdom. E-mail: rusi.jaspal@gmail.com

\section{ACKNOWLEDGEMENTS}

The author would like to thank the Changing Faces Charity for their encouragement and endorsement of this article. 


\section{Disfigurement: the challenges for identity and the strategies for coping}

Living with disfigurement can constitute a psychologically challenging position for both adults and young people alike. The present paper explores the potential implications of living with disfigurement for identity through the novel application of identity process theory, a socio-psychological theory of identity threat, to the topic of disfigurement. The theory argues that individuals need to perceive appropriate levels of self-esteem, distinctiveness, continuity, selfefficacy, meaning, belonging and coherence, and that insufficient levels of these principles will induce identity threat. Firstly, the paper outlines those principles most susceptible to threat among individuals living with disfigurement. Secondly, it considers strategies which may be implemented by the threatened individual as a means of coping with identity threat associated with disfigurement, as well as the efficacy of these strategies. The primary focus of the paper lies within the identification of what threatens identity and how health care institutions can facilitate and encourage effective coping strategies among individuals living with disfigurement. (155 words)

Living with disfigurement can constitute a psychologically challenging position for both adults and young people alike. The affected individual may face socio-psychological difficulties in adjusting to their disfigurement. In particular, the stigma of disfigurement may have negative outcomes for self-esteem, self-confidence and interpersonal relations with others. Thus, it is unfortunate that the important link between disfigurement and the self-concept has been neglected by researchers. The present paper aims to address this lacuna by applying a sociopsychological theory of identity threat to disfigurement. Firstly, the paper outlines those identity 
principles, likely to be susceptible to change as a result of disfigurement. Secondly, it considers strategies which may be implemented by the individual as a means of coping with identity threat associated with disfigurement, as well as the efficacy of these strategies. A consideration of the central tenets of identity process theory may assist health care institutions to realise their goal of supporting young people's socio-psychological adjustment to disfigurement.

Identity process theory ${ }^{1}$ provides an integrative theory of identity threat and coping, by outlining (i) the necessary components of a positive identity; (ii) social situations likely to 'threaten' identity and (iii) the strategies likely be implemented by the individual in order to cope with the threat. It is argued that the individual needs to perceive appropriate levels of selfcontinuity across time (continuity); uniqueness and differentiation from relevant others (distinctiveness); competence and control over their lives and future (self-efficacy); feelings of personal worth (self-esteem); significance and purpose within their lives (meaning); belonging within social groups (belonging); and compatibility and coherence between elements of their identities (psychological coherence). The theory holds that if the individual cannot perceive appropriate levels of these principles, identity is threatened, which is aversive for psychological well-being. Although it is possible that all or most of these principles may be threatened as a result of living with disfigurement, the present paper considers those principles, which are most susceptible to threat, namely (i) continuity; (ii) self-esteem; (iii) distinctiveness; and (iv) selfefficacy. A key tenet of the theory suggests that the individual will seek to alleviate the threat by engaging in intrapsychic coping strategies, which function at the level of the individual; interpersonal strategies, which involve interaction with other individuals; and intergroup strategies, which refer to group-level behaviour. Some coping strategies are inherently more efficacious than others ${ }^{2}$. The present paper offers fresh insights into the interface of disfigurement and identity threat by considering disfigurement through the lens of IPT.

\footnotetext{
${ }^{1}$ Breakwell (1986); Jaspal \& Cinnirella (2010)

${ }^{2}$ Breakwell (1986)
} 


\section{Identity threat}

Self-esteem The concept of stigma is vital in understanding the psychosocial effects of disfigurement. The stigmatised individual may be 'devalued, spoiled, or flawed in the eyes of others'3. Clearly, stigmatisation on the basis of one's disfigurement, which may be difficult or impossible to conceal, is unlikely to be conducive to a positive self-conception, since the stigmatised individual may come to perceive decreased personal worth ${ }^{4}$. Indeed, scholars argue that feeling 'flawed' reflects one dimension of the stigma associated with disfigurement ${ }^{5}$. Crucially, stigmatisation and self-esteem are negatively correlated, which suggests that increases in stigma will induce decreases in self-esteem ${ }^{6}$. Empirical research attests to the vulnerability of the self-esteem principle among individuals with a disfigurement (IWD). A survey study revealed significantly higher levels of psychological distress among IWD than participants from the normative group ${ }^{7}$. The interpersonal dimension of threats to self-esteem cannot be underestimated; the individual's perception that others hold a negative perception of him/her may well result in threats to self-esteem. This need not necessarily relate to overt name-calling or ridicule from others ${ }^{8}$, but may be expressed in more subtle ways. For instance, the individual's perception that others are wary of engaging in interpersonal contact with him/her due to a disfigurement or the perception that one is given (unfavourable) attention due to their disfigurement may lead to a negative self-conception and hence decreased self-esteem.

Distinctiveness The notion that the individual is given excessive attention as a result of their disfigurement highlights how the distinctiveness principle may in fact threaten identity. Clearly,

${ }^{3}$ Crocker et al. (1998, p. 504)

${ }^{4}$ Goffman (1963)

${ }^{5}$ Ginsburg \& Link (1989)

${ }^{6}$ Jaspal (2011)

${ }^{7}$ Rumsey et al. (2004)

${ }^{8}$ cf. Partridge (1997); Krishna (2009) 
the fact that only one Briton in 111 has a significant facial disfigurement highlights the relative rarity of occupying this position ${ }^{9}$. Thus, IWD are automatically differentiated from the majority as a result of their appearance. Crucially, the individual must perceive appropriate levels of distinctiveness ${ }^{10}$. It is easy to see how 'excessive' distinctiveness might conversely threaten one's sense of belonging within a social group or society as a whole, which is equally as important for identity ${ }^{11}$. IWD may exclude themselves from social activities or avoid applying for certain occupations due to the anticipation that they will be excluded by relevant others as a result of their 'excessive' distinctiveness ${ }^{12}$. Thus, while the other principles may be curtailed as a result of disfigurement, the distinctiveness principle may become excessively 'active' in social encounters with members of the general population, resulting in identity threat.

Self-efficacy There is empirical evidence that IWD may experience threats to the self-efficacy principle of identity, given that they may perceive a weak sense of control and competence over their lives and future. In a study on disfiguring burn scars, self-efficacy and self-esteem ${ }^{13}$, adolescent participants with disfiguring burns reported significantly lower self-competence than the normative group, suggesting that the disfigurement has negative outcomes for self-efficacy. IWD may feel less able to realise certain goals in their lives as a direct result of the social stigma surrounding disfigurement. For instance, IWD may regard certain occupations to be 'off limits' or attendance at certain social events to be impossible due to their disfigurement. Crucially, it is the wish to accomplish a specific goal coupled with the simultaneous perception that one is unable to accomplish it, which threatens self-efficacy.

\footnotetext{
${ }^{9}$ Changing Faces Online

${ }^{10}$ Breakwell (1986)

${ }^{11}$ Vignoles et al. (2006)

12 Ginsburg \& Link (1989)

${ }^{13}$ Robert et al. (1999)
} 
Continuity Individuals who acquire a disfigurement later on in life are particularly susceptible to threats to continuity, primarily because they must assimilate within their self-concept an undesirable and, in many cases, unanticipated change ${ }^{14}$. Individuals are required to adjust to changes both in their physical appearance and in interpersonal relations with others ${ }^{15}$. It may be difficult to establish a psychological thread unifying past, present and future, given the suddenness of disfigurement, particularly when induced by an accident, for instance. Moreover, the uncertainties associated with living with disfigurement, particularly in relation to securing employment and realising other future goals, may jeopardise the connection between past and future. In some cases, threats to continuity may be chronic, since IWD may be exposed to family photographs and other social stimuli evoking memories of their lives prior to disfigurement. The constant, enforced psychological transition between past and present, in the absence of a unifying psychological thread, may render salient the psychological disconnect within one's sense of self.

\section{Coping}

There is much empirical research that suggests that disfigurement poses threats to identity. In particular, it seems that continuity, self-esteem and self-efficacy will be threatened, while distinctiveness will be excessively active. According to IPT, this will induce coping strategies on the part of threatened individuals. Individuals will seek to cope at three levels: the intrapsychic, the interpersonal and the intergroup.

The intrapsychic dimension of coping is important, since it involves the individual's personal meaning-making vis-à-vis disfigurement. On the onset of disfigurement it is possible that the individual will engage in the deflection strategy of denial by refusing to look at him/herself in the mirror and by rejecting the reality of their disfigurement. This is a transient

\footnotetext{
${ }^{14}$ Breakwell (1986)

${ }^{15}$ Bradbury (1997)
} 
strategy, which is unlikely to be effective in the long-run ${ }^{16}$. However, it is important to facilitate the individual's acceptance of their disfigurement so that a fundamental change within the identity structure may take place. Continuity, self-esteem and self-efficacy will likely be threatened as a consequence of accepting disfigurement, but 'once the change to identity (i.e. acceptance of one's disfigurement) is wrought, the threat is passed ${ }^{17}$. Clearly, this acceptance strategy will be markedly more successful in the long-run if the individual is able to re-interpret their social position (as a person with a disfigurement) and re-define the reasons for occupying this social position. For instance, the individual should be encouraged to conceptualise their disfigurement not in terms of a 'flaw' but rather as an aspect of 'who one is'. The change in appearance should be construed by the individual as an aspect of their identity. Furthermore, the individual must establish that essential unifying thread between past and present by constructing a consistent life-story. This is important for coping with major life events, such as disfigurement. Thus, the strategies of re-interpretation and re-definition may be conducive to the efficacious acceptance strategy of incorporating fundamental change within identity.

The individual will try to cope at the interpersonal level. IWD may avoid interpersonal contact by engaging in the strategy of isolation. IPT regards isolation as 'more of an inaction strategy than an action strategy ${ }^{18}$. Like denial, this will only be effective in the short term since, although the principles of self-esteem and self-efficacy may be salvaged by obliterating the source of the threat (i.e. others' responses to disfigurement), the belonging principle will eventually face threats. The individual needs to feel acceptance and inclusion within society as a whole, yet the isolation strategy directly impedes this. The intergroup strategy of group support, which refers to self-inclusion within consciousness-raising/self-help groups, is likely to alleviate the threats to belonging initially posed by self-isolation. This elucidates the immense importance of organisations such as Changing Faces, which provide social support to IWD. In

\footnotetext{
${ }^{16}$ Breakwell (1986)

${ }^{17}$ Breakwell (1986, p. 96)

${ }^{18}$ Breakwell (1986, p. 109)
} 
these social contexts, individuals are able to establish feelings of self-esteem in a supportive non-stigmatising social environment; self-efficacy through exposure to narratives of success and future possibility; continuity through the collective exploration of past, present and future; and belonging within a social group.

Health care institutions committed to the support of IWD must continue to facilitate the acceptance strategy advocated in this paper. The re-interpretation of what disfigurement means socially will undoubtedly impact the psychological meanings of disfigurement. Health care services may help to change the characteristics (i.e. stereotypes) associated with the social position of being disfigured. For instance, Changing Faces acknowledges that some individuals may not feel comfortable with the term 'disfigurement' but may prefer 'visible difference'. The appropriate use of terminology is essential for facilitating positive changes in the social representation of disfigurement. This will likely have positive outcomes for self-esteem among IWD.

Furthermore, health care institutions must continue to provide IWD with the social and information networks and consciousness-raising groups, which are so pivotal in providing individuals with feelings of self-esteem, continuity, self-efficacy and belonging. While these groups should initially constitute a collective context for IWD, the encouragement of positive interpersonal relations between IWD and members of the general population would possibly allow IWD to engage in overt discussions regarding their disfigurement with others. This will likely reduce the excessive distinctiveness of IWD, while facilitating feelings of acceptance from others and inclusion within the broader society. Moreover, this may contribute to the dismantlement of stigma in the eyes of IWD. Health care must include the restoration of feelings of self-efficacy. Indeed, previous research demonstrates that this principle may be acutely vulnerable to threat. Health care must include the provision of social contexts, in which success stories can be shared, elucidating the potential benefits for self-efficacy. Social influence processes may be particularly active among individuals in a similar social situation, 
with the result that feelings of self-efficacy may be transmitted to one another and thus collectively 'shared'.

Health care services alone cannot accomplish the task of ameliorating identity processes among young IWD. Rather, this must be a collective endeavour. The media, in particular, has a crucially important role to play in changing social representations of disfigurement. This will undoubtedly complement the hard work currently being undertaken by health care services and, at the social level at least, will have immense clout in improving public attitudes and in obliterating social stigma towards disfigurement.

1998 words (excluding abstract and references)

\section{References}

Bradbury, E. (1997). Understanding the problems. In R. Lansdown, N. Rumsey, E. Bradbury, A. Carr, \& J. Partridge (Eds.), Visibly different: Coping with disfigurement (pp. 180-193). Oxford: Butterworth-Heinemann.

Breakwell, G.M. (1986) Coping with Threatened Identities. London: Methuen.

Changing Faces, The Face Equality Campaign. [Online]. Changing Faces, The Squire Centre, 33-37 University Street, London, WC1E 6JN, UK. [Accessed: 14th November 2010] Available from: http://www.changingfaces.org.uk/Face-Equality

Crocker, J., Major, B., \& Steele, C. (1998). Social Stigma. In Gilbert, D., Fiske, S. T., \& Lindzey, G. (Eds.), The Handbook of Social Psychology (4th ed., Vol. 2, pp. 504-553). New York: McGraw Hill.

Ginsburg I. \& Link B. (1989) Feelings of stigmatization in patients with psoriasis. Journal of the American Academy of Dermatology, 20: 53-63.

Goffman, E. (1963). Stigma: notes on the management of spoiled identity. Prentice-Hall: Englewood Cliffs, NJ. 
Jaspal, R. (2011). Caste, social stigma and identity processes. Psychology and Developing Societies, 23(2), 27-62.

Jaspal, R. \& Cinnirella, M. (2010). Coping with potentially incompatible identities: accounts of religious, ethnic and sexual identities from British Pakistani men who identify as Muslim and gay. British Journal of Social Psychology, 49(4), 849-870.

Partridge (1997). Facial disfigurement: both counseling for patients and education for the public are necessary. British Medical Journal, 315(7100), 120.

Robert, R., Meyer, W., Bishop, S., Rosenberg, L., Murphy, L. \& Blakeney, P. (1999). Disfiguring burns scars and adolescent self-esteem. Burns, 25(7), 581-85.

Rumsey, N., Clarke, A., White, P., Wyn-Williams, M. \& Garlick, W. (2004). Altered body image: appearance-related concerns of people with visible disfigurement. Journal of Advanced Nursing, 48(5), 443-453.

Vignoles, V. L., Chryssochoou, X., \& Breakwell, G. M. (2000). The distinctiveness principle: Identity, meaning and the bounds of cultural relativity. Personality and Social Psychology Review, 4, 337-354. 